\title{
Cholinergic manipulations bidirectionally regulate object memory destabilization
}

\author{
Mikaela L. Stiver, ${ }^{1}$ Derek L. Jacklin, ${ }^{1}$ Krista A. Mitchnick, Nevena Vicic, Justine Carlin, \\ Matthew O'Hara, and Boyer D. Winters \\ Department of Psychology and Neuroscience Program, University of Guelph, Guelph, Ontario N1G 2W1, Canada
}

\begin{abstract}
Consolidated memories can become destabilized and open to modification upon retrieval. Destabilization is most reliably prompted when novel information is present during memory reactivation. We hypothesized that the neurotransmitter acetylcholine ( $\mathrm{ACh}$ ) plays an important role in novelty-induced memory destabilization because of its established involvement in new learning. Accordingly, we investigated the effects of cholinergic manipulations in rats using an object recognition paradigm that requires reactivation novelty to destabilize object memories. The muscarinic receptor antagonist scopolamine, systemically or infused directly into the perirhinal cortex, blocked this novelty-induced memory destabilization. Conversely, systemic oxotremorine or carbachol, muscarinic receptor agonists, administered systemically or intraperirhinally, respectively, mimicked the destabilizing effect of novel information during reactivation. These bidirectional effects suggest a crucial influence of $\mathrm{ACh}$ on memory destabilization and the updating functions of reconsolidation. This is a hitherto unappreciated mnemonic role for $\mathrm{ACh}$ with implications for its potential involvement in cognitive flexibility and the dynamic process of long-term memory storage.
\end{abstract}

[Supplemental material is available for this article.]

Reactivation or recall can render previously consolidated memories labile and sensitive to modification; this necessitates a timedependent process, referred to as reconsolidation, to restabilize the memory (Lewis 1979; Nader et al. 2000; Sara 2000; Lee 2009; Nader and Hardt 2009). Whereas much research has elucidated the neural mechanisms subserving post-retrieval reconsolidation (Alberini 2005; Tronson and Taylor 2007; Nader and Hardt 2009), the neural bases of reactivation-induced memory destabilization have only recently received the same kind of attention (Lee 2009; Kaang and Choi 2011). A better understanding of the behavioral and neural factors contributing to memory destabilization is crucial given its permissive role in the reconsolidation process. Indeed, not all memories become labile when reactivated; boundary conditions, including the strength of initial memory encoding and the age of the memory at the time of retrieval, determine the likelihood of destabilization upon reactivation (Milekic and Alberini 2002; Eisenberg and Dudai 2004; Suzuki et al. 2004; Winters et al. 2009). These boundary conditions may be related to the putative role of reconsolidation in memory updating (Sara 2000; Rodriguez-Ortiz et al. 2005; Morris et al. 2006; Hupbach et al. 2007; Rossato et al. 2007; Lee 2009; Forcato et al. 2010; Sevenster et al. 2013). Accordingly, stronger or more remote memories may be less likely to be altered in the absence of salient novel information (Lee 2009; Winters et al. 2009). Thus, novelty-induced memory destabilization, as the essential gateway to the reconsolidation process, is probably crucial to the adaptive functions of memory modification (Lee 2008, 2009; Choi et al. 2010).

Recently, a better understanding of the neural mechanisms underlying memory destabilization-i.e., the return of memories to a labile state after reactivation-has begun to take shape (Ben Mamou et al. 2006; Lee et al. 2008; Suzuki et al. 2008; Choi et al. 2010; Hong et al. 2013; Milton et al. 2013). For example, deg-

1These authors contributed equally to this work.

Corresponding author: bwinters@uoguelph.ca

Article is online at http://www.learnmem.org/cgi/doi/10.1101//m.037713.114. radation of synaptic proteins via ubiquitin proteasome system (UPS) activation likely underlies the putative synaptic uncoupling of the memory trace that could enable various forms of potential memory modification during the destabilization period (e.g., erasure or weakening, updating, strengthening) (Lee 2008; Lee et al. 2008; Choi et al. 2010). Despite these advances, few studies have directly addressed the connection between memory destabilization and conditions favoring novel information encoding (Morris et al. 2006; Winters et al. 2009). Recently, however, Reichelt et al. (2013) demonstrated the important role that dopaminergic transmission may play in relation to prediction error. A further key piece of this puzzle may be the neurotransmitter acetylcholine (ACh), which is strongly implicated in various cognitive functions related to new learning, such as attention, arousal, and novel memory encoding (Sarter and Bruno 1997; Giovannini et al. 2001; Hasselmo and McGaughy 2004; Winters et al. 2006). We therefore hypothesized that cholinergic receptor activation in response to new learning opportunities during memory reactivation is an important trigger for intracellular mechanisms of memory destabilization.

Using the spontaneous object recognition (SOR) paradigm for rats, we previously demonstrated that relatively remote or more strongly encoded object memories were only destabilized when reactivated in the presence of a salient novel contextual cue (a textured floor insert, Winters et al. 2009). Our group and others have also previously demonstrated the involvement of the perirhinal cortex (PRh) in object memory reconsolidation (Romero-Granados et al. 2010; Winters et al. 2011; Balderas et al. 2013). Given the established role of ACh in information

(C) 2015 Stiver et al. This article is distributed exclusively by Cold Spring Harbor Laboratory Press for the first 12 months after the full-issue publication date (see http://learnmem.cshlp.org/site/misc/terms.xhtml). After 12 months, it is available under a Creative Commons License (AttributionNonCommercial 4.0 International), as described at http://creativecommons. org/licenses/by-nc/4.0/. 
encoding in the SOR task (Warburton et al. 2003; Winters et al. 2006, 2007), we hypothesized that the novelty-induced object memory destabilization demonstrated in our previous study was triggered by cholinergic transmission at muscarinic receptors within PRh. Here we provide support for this hypothesis, showing that systemic and intra-PRh administration of muscarinic receptor antagonists or agonists prevent or facilitate object memory destabilization, respectively.

\section{Results}

\section{Experiment 1: systemic muscarinic receptor antagonism prevents object memory destabilization}

In Experiment $1 \mathrm{a}$, in the absence of scopolamine, injections of MK-801 disrupted reconsolidation of reactivated object recognition memories in the "standard" SOR reconsolidation paradigm; however, coadministration of scopolamine prevented this effect (Fig. 1A). One-way repeated-measures analysis of variance (ANOVA) on the discrimination ratio data from the choice phase revealed a significant drug effect $\left(F_{(3,33)}=8.96 ; P<0.001\right)$. Post hoc comparisons indicated that performance under the saline/ MK-801 drug condition differed significantly from saline/saline $\left(t_{(11)}=2.8 ; \quad P=0.017\right), \quad$ scopolamine/saline $\left(t_{(11)}=4.52 ; \quad P=\right.$ $0.001)$, and scopolamine $/ \mathrm{MK}-801\left(t_{(11)}=-6.14 ; P<0.001\right)$ trials. Moreover, one-sample $t$-tests comparing performance in each drug condition to 0 (i.e., chance performance, no object preference in the choice phase) indicated significant novel object preference in all conditions (all $P<0.01$ ), except for saline/ MK-801 $(P=0.986)$. There were no significant differences in any of the control measures analyzed (all $P>0.05$ ), indicating that animals in all drug conditions showed similar general object exploration behavior in the sample, reactivation, and choice phases (means and SEMs were consistent with previously established values Winters et al. 2009). Control measure values for each experiment are presented in Supplemental Table S1. Moreover, because of the within-subjects nature of the experimental design, we assessed all experiments for changes in overall object exploration between trials 1-4; however, there were no consistent reductions in sample or choice object exploration from trials 1-4 in any of the experiments when collapsed across drug conditions (data not shown).

In Experiment $1 \mathrm{~b}$ combined systemic injections of saline and MK-801 given $24 \mathrm{~h}$ after the sample phase had no effect on object recognition when the reactivation phase was omitted $\left(F_{(3,33)}=0.07 ; P=0.975\right.$; Fig. $\left.1 \mathrm{~B}\right)$. Rats in all conditions also demonstrated significant novel object preference in the choice phase (all $P<0.001$ ).

Experiment 1c was designed to ensure that scopolamine did not prevent the MK-801-induced deficit by blocking memory retrieval during the reactivation phase. The same parameters were used as in Experiment 1a, except that a novel object replaced one of the familiar objects in the reactivation phase (A and $\mathrm{B})$ and a different novel object was used during the choice phase (A and C). This allowed us to assess the performance of rats during the reactivation phase and determine if scopolamine was indeed influencing memory retrieval. A nonsignificant one-way repeated-measures ANOVA of the discrimination ratio data obtained during the reactivation phase indicated intact memory retrieval for all drug conditions $\left(F_{(3,33)}=0.28 ; P>0.05\right.$; Fig. $\left.2 \mathrm{~A}\right)$. This was further verified as separate one-sample $t$-tests comparing performance to 0 revealed that a significant preference for the novel object was present in all drug conditions (all $P<0.001$ ). Results from the choice phase replicated the findings from Experiment 1a; MK-801 given during reactivation disrupted reconsolidation, and this effect was prevented when scopolamine
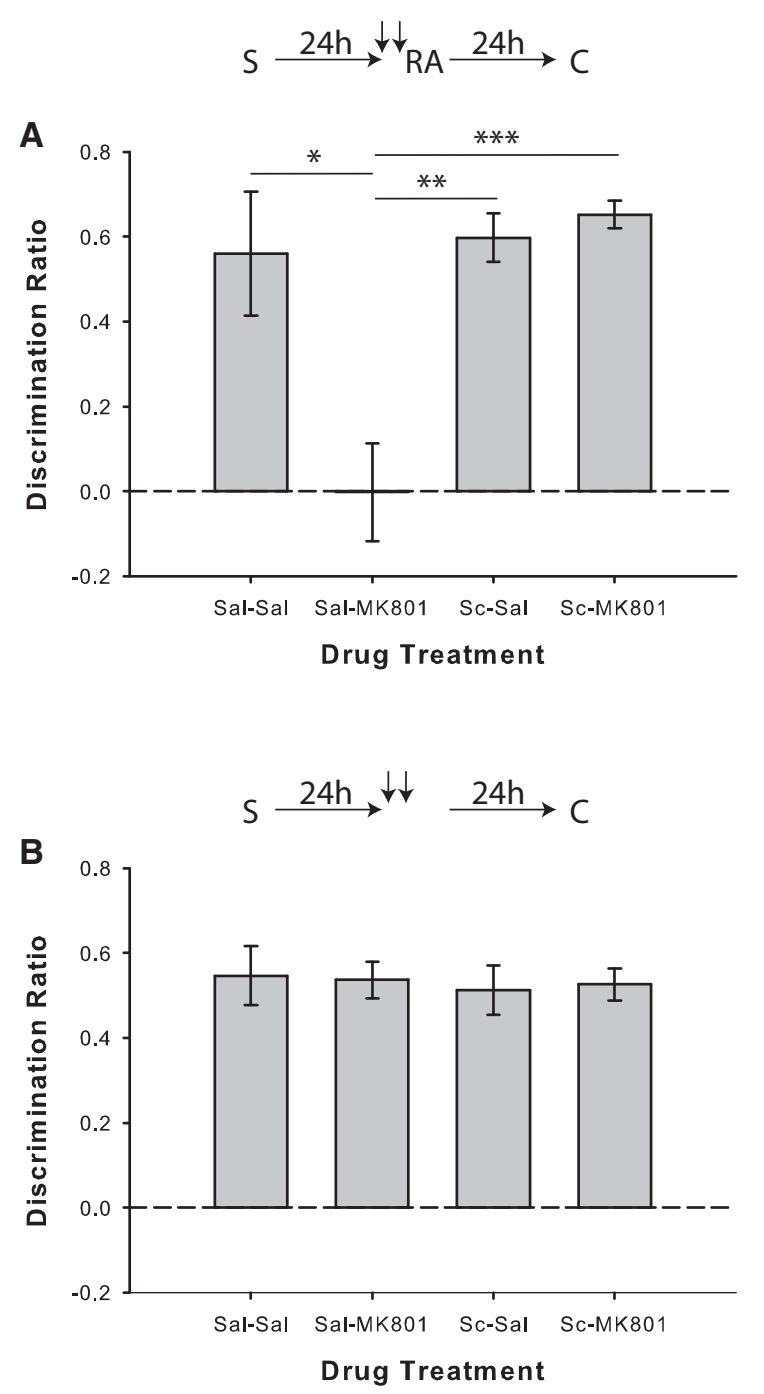

Figure 1. Muscarinic cholinergic receptor blockade with scopolamine prevents object memory destabilization. $(A)$ Object recognition performance by rats in Experiment 1a $(n=12)$. Coadministration of scopolamine $(\mathrm{Sc})$ prior to memory reactivation blocked the MK-801-induced reconsolidation deficit. Rats in all drug conditions except for saline/ MK-801 showed significant novel object preference in the choice phase, as indicated by separate one-sample t-tests versus chance (0). (B) Experiment $1 \mathrm{~b}(n=12)$, in which the reactivation phase was omitted, confirmed that the MK-801-induced impairment was reactivationdependent. All conditions discriminated significantly above chance according to one-sample $t$-tests. Data are presented as average discrimination ratio \pm SEM. For all graphs, upper schematics indicate behavioral procedures used for specific experiments. (S) Sample phase, (RA) reactivation phase, $(C)$ choice phase, downward arrows represent drug injections. $\left({ }^{*}\right) P<0.05$; (**) $P<0.01$; (***) $P<0.001$.

was coadministered with MK-801 (Fig. 2B). One-way repeatedmeasures ANOVA on the discrimination ratio data from the choice phase revealed a significant drug effect $\left(F_{(3,33)}=11.84 ; P<\right.$ 0.001). Post hoc comparisons showed that performance in the saline/MK-801 condition was significantly worse than the saline/ saline $\left(t_{(11)}=3.65 ; P<0.01\right)$, scopolamine/saline $\left(t_{(11)}=4.77\right.$; $P<0.01)$ and scopolamine $/ \mathrm{MK}-801\left(t_{(11)}=3.70 ; P<0.01\right)$ conditions. Furthermore, one-sample $t$-tests comparing performance to 0 indicated that preference for the novel object was significantly above chance levels in all drug conditions (all $P<0.001$ ), except for saline/MK-801 $(P=0.636)$. Thus, it appears that the effect of 


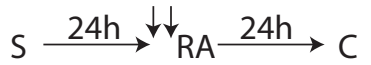

A
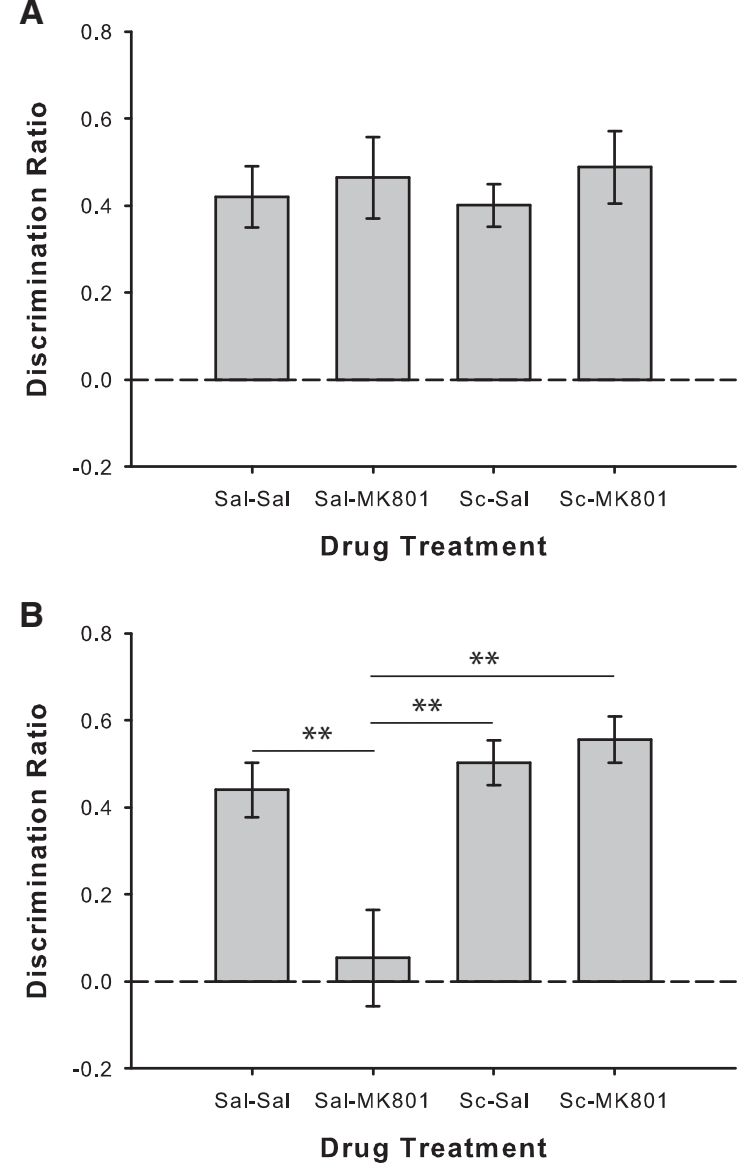

Figure 2. Scopolamine does not prevent object memory retrieval during the reactivation phase. $(A)$ Object recognition performance by rats in the reactivation phase of Experiment 1c $(n=12)$. A novel object was presented along with a copy of the sample object to enable measurement of recognition during the reactivation phase. Administration of scopolamine (Sc) prior to memory reactivation did not disrupt recognition. Rats in all drug conditions showed significant novel object preference. (B) Object recognition performance by rats in the choice phase of Experiment 1c. As in Experiment 1a, prereactivation scopolamine prevented the reconsolidation impairment caused by MK-801. Data are presented as average discrimination ratio \pm SEM. $(* *) P<0.01$.

scopolamine during the reactivation phase may be specific to memory destabilization rather than retrieval per se, as rats were able to demonstrate accurate object recognition during the modified reactivation phase in Experiment 1c.

\section{Experiment 2: novelty-induced destabilization of strongly encoded object memories requires muscarinic receptor activation}

In Experiment $2 \mathrm{a}$, as previously demonstrated (Winters et al. 2009), systemic MK-801 paired with saline disrupted SOR performance when a salient novel contextual stimulus (a textured floor insert) was present during the reactivation of strongly encoded object memories; conversely, pairing scopolamine with MK-801 prevented this impairment (Fig. 3A). ANOVA on the discrimination ratio scores indicated a significant drug effect $\left(F_{(3,27)}=\right.$ $3.17 ; P=0.04)$. Performance on saline/MK-801 trials differed sig- nificantly from saline/saline $\left(t_{(9)}=2.82 ; P=0.02\right.$, one-tailed test) and scopolamine/MK-801 $\left(t_{(9)}=3.54 ; P=0.006\right)$ conditions. There was also significant novel object preference in all conditions (all $P<0.01)$, except for saline/MK-801 $(P=0.367)$.

Experiment $2 \mathrm{~b}$ was run to confirm that salient reactivation phase novelty was required to demonstrate the impairment produced by MK-801 in Experiment 2a. Paired systemic administration of saline and MK-801 prior to memory reactivation had no effect on object recognition when the floor insert was omitted from the reactivation phase $\left(F_{(3,27)}=0.8 ; P=0.505\right.$; Fig. $\left.3 \mathrm{~B}\right)$, and rats in all conditions showed significant novel object preference in the choice phase (all $P<0.05$ ).
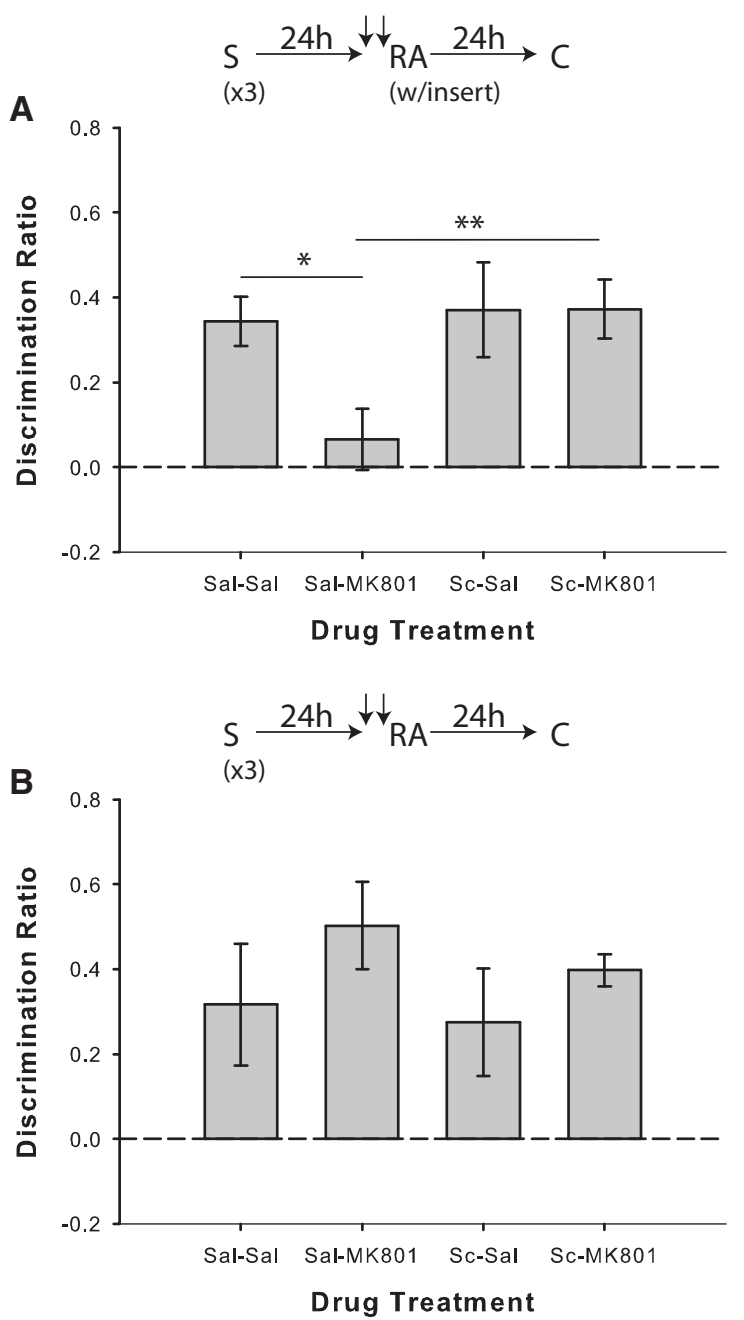

Figure 3. Muscarinic cholinergic receptor blockade with scopolamine prevents novelty-induced destabilization of strongly encoded object memories. (A) Object recognition performance by rats in Experiment $2 \mathrm{a}(n=$ 10). Coadministration of scopolamine (Sc) before memory reactivation blocked the MK-801-induced memory reconsolidation impairment observed when strongly encoded object memories (from three sampling sessions) were reactivated in the presence of a salient novel contextual cue ("insert"). Separate one-sample $t$-tests versus chance $(0)$ indicated that rats in all drug conditions except for Saline/MK-801 showed significant novel object preference in the choice phase. (B) Experiment $2 \mathrm{~b}(n=10)$, in which the reactivation phase was conducted without the novel cue, confirmed that the MK-801-induced deficit was reliant on the presence of salient novelty in the reactivation phase. Rats in all conditions discriminated significantly above chance according to one-sample $t$-tests. Data are presented as average discrimination ratio \pm SEM. $\left({ }^{*}\right) P<0.05 ;(* *) P<0.01$. 
Experiment 3: novelty-induced destabilization of relatively remote object memories requires muscarinic receptor activation

In Experiment 3a, as previously reported (Winters et al. 2009), systemic MK-801 coadministered with saline disrupted SOR performance when the floor insert was present during reactivation of relatively remote object memories; however, pairing scopolamine with MK-801 prevented this impairment (Fig. 4A). A univariate ANOVA on the discrimination ratio scores indicated a significant drug effect $\left(F_{(3,33)}=4.01 ; P=0.015\right)$, and post hoc analyses revealed that performance in the saline/MK-801 condition differed significantly from saline/saline $\left(t_{(11)}=3.37 ; P=0.006\right)$ and sco-
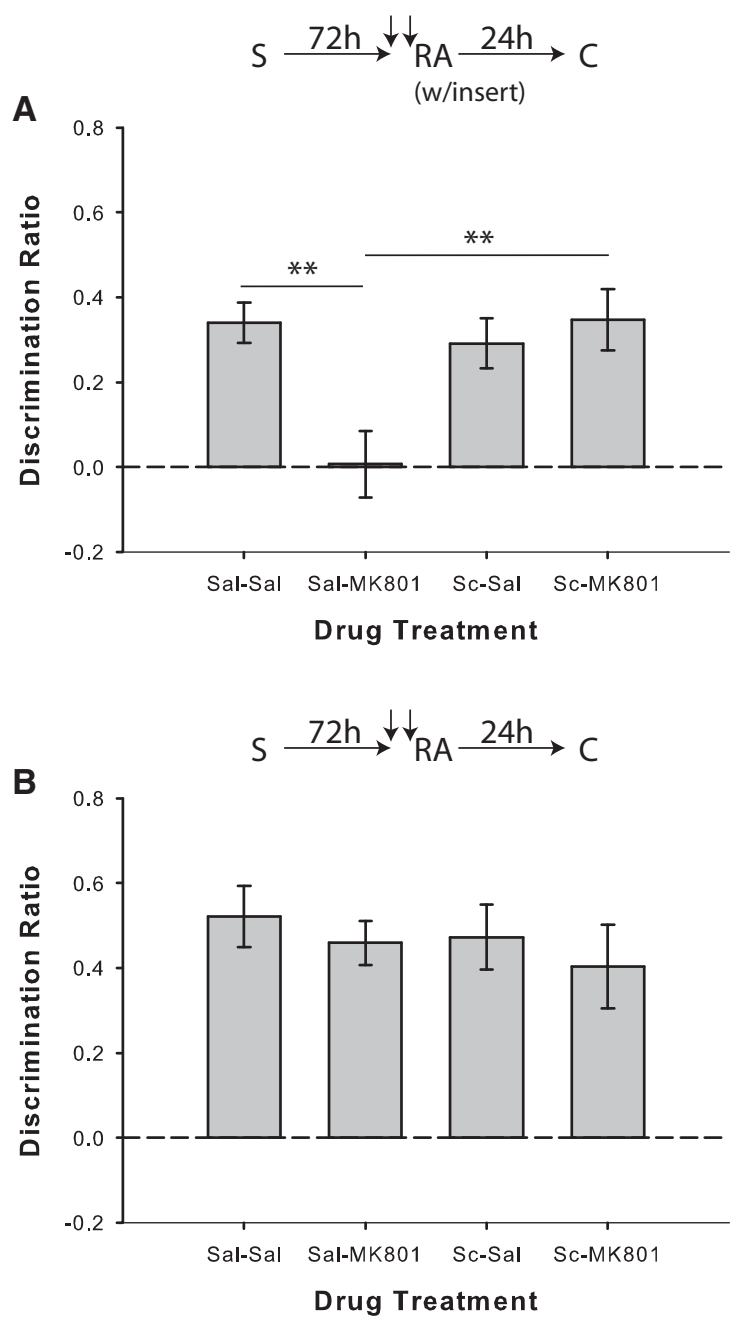

Figure 4. Muscarinic cholinergic receptor blockade with scopolamine prevents novelty-induced destabilization of relatively remote object memories. (A) Object recognition performance by rats in Experiment 3a $(n=$ 12). Coadministration of scopolamine prior to memory reactivation blocked the MK-801-induced memory reconsolidation impairment observed when relatively remote object memories $(72 \mathrm{~h}$ delay between sample and reactivation) were reactivated in the presence of a salient novel contextual cue ("insert"). Separate one-sample $t$-tests versus chance (0) indicated that rats in all drug conditions except for Saline/ MK-801 showed significant preference for the novel object. (B) Experiment $3 \mathrm{~b}(n=10)$, in which the reactivation phase was conducted without the novel cue, confirmed that the MK-801-induced deficit required the presence of salient novelty in the reactivation phase. All conditions discriminated significantly above chance according to one-sample $t$-tests. Data are presented as average discrimination ratio \pm SEM. $\left.{ }^{* *}{ }^{*}\right) P<0.01$.
polamine/MK-801 $\left(t_{(11)}=3.21 ; P=0.008\right)$ conditions. Rats displayed significant novel object preference in all conditions (all $P<0.01)$, except for saline/MK-801 $(P=0.527)$.

In Experiment 3b, coadministration of saline and MK-801 prior to memory reactivation did not affect object recognition when the floor insert was omitted from the reactivation phase $\left(F_{(3,27)}=0.39 ; P=0.764 ;\right.$ Fig. 4B), and rats showed significant novel object preference in the choice phase in all conditions (all $P<0.01)$.

\section{Experiment 4: muscarinic receptor agonism during} reactivation of strongly encoded object memories mimics the destabilizing effect of salient novelty

Results from Experiment 4a replicated the lack of reconsolidation impairment for strongly encoded memories in the saline/MK-801 condition when memory reactivation was performed in the absence of salient novelty; conversely, object recognition was disrupted on trials in which rats received coadministration of oxotremorine and MK-801 before the reactivation phase (Fig. 5A). ANOVA revealed a significant drug effect $\left(F_{(3,57)}=6.74 ; P=\right.$ 0.001 ), and post hoc analyses indicated that performance in the oxotremorine/MK-801 condition differed significantly from saline/saline $\left(t_{(19)}=2.6 ; P=0.017\right)$, saline $/ \mathrm{MK}-801\left(t_{(19)}=3.9 ; P=\right.$ $0.001)$, and saline/oxotremorine $\left(t_{(19)}=2.72 ; P=0.014\right)$ trials. Rats showed significant novel object preference in all conditions (all $P<0.001)$, except for oxotremorine/MK-801 $(P=0.164)$.

In Experiment $4 \mathrm{~b}$, coadministration of oxotremorine and MK-801 $24 \mathrm{~h}$ after the last sample phase did not affect object recognition memory when the reactivation phase was omitted (paired-samples $t$-test versus saline/saline: $t_{(7)}=0.57 ; P=0.589$; Fig. 5B), and significant novel object preference was demonstrated by rats on both types of trials (both $P<0.01$ ).

\section{Experiment 5: muscarinic receptor agonism during reactivation of relatively remote object memories mimics the destabilizing effect of salient novelty}

Results from Experiment 5a replicated the lack of reconsolidation disruption in the saline/MK-801 condition when reactivation of relatively remote object memories was performed without the floor insert; object recognition was, however, disrupted on trials in which rats received paired injections of oxotremorine and MK-801 before the reactivation phase (Fig. 6A). There was a significant drug effect $\left(F_{(3,33)}=23.55 ; P<0.001\right)$, and post hoc analyses revealed impaired performance in the oxotremorine/MK-801 condition relative to saline/saline $\left(t_{(11)}=6.49 ; P<0.001\right)$, saline/MK-801 $\left(t_{(11)}=6.06 ; P<0.001\right)$, and saline/oxotremorine $\left(t_{(11)}=7.01 ; P<0.001\right)$ conditions. Rats showed significant novel object preference in all conditions (all $P<0.001$ ), except for oxotremorine/MK-801 $(P=0.514)$.

In Experiment $5 \mathrm{~b}$, coadministration of oxotremorine and MK-801 $48 \mathrm{~h}$ after the sample phase did not affect object recognition memory when the reactivation phase was omitted (pairedsamples $t$-test versus saline/saline: $t_{(11)}=0.85 ; P=0.415$; Fig. $6 \mathrm{~B})$, and rats showed significant novel object preference on both trial types (both $P>0.05$ ).

\section{Experiment 6: blockade of muscarinic receptors in perirhinal cortex prevents object memory destabilization} The perirhinal cortex (PRh) has been strongly implicated in aspects of object memory and representation (Buckley 2005; Murray et al. 2007; Winters et al. 2008; Brown et al. 2012). We therefore paired prereactivation intra-PRh infusions of saline or scopolamine with post-reactivation infusions of the protein 


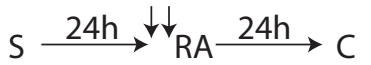

(x3)
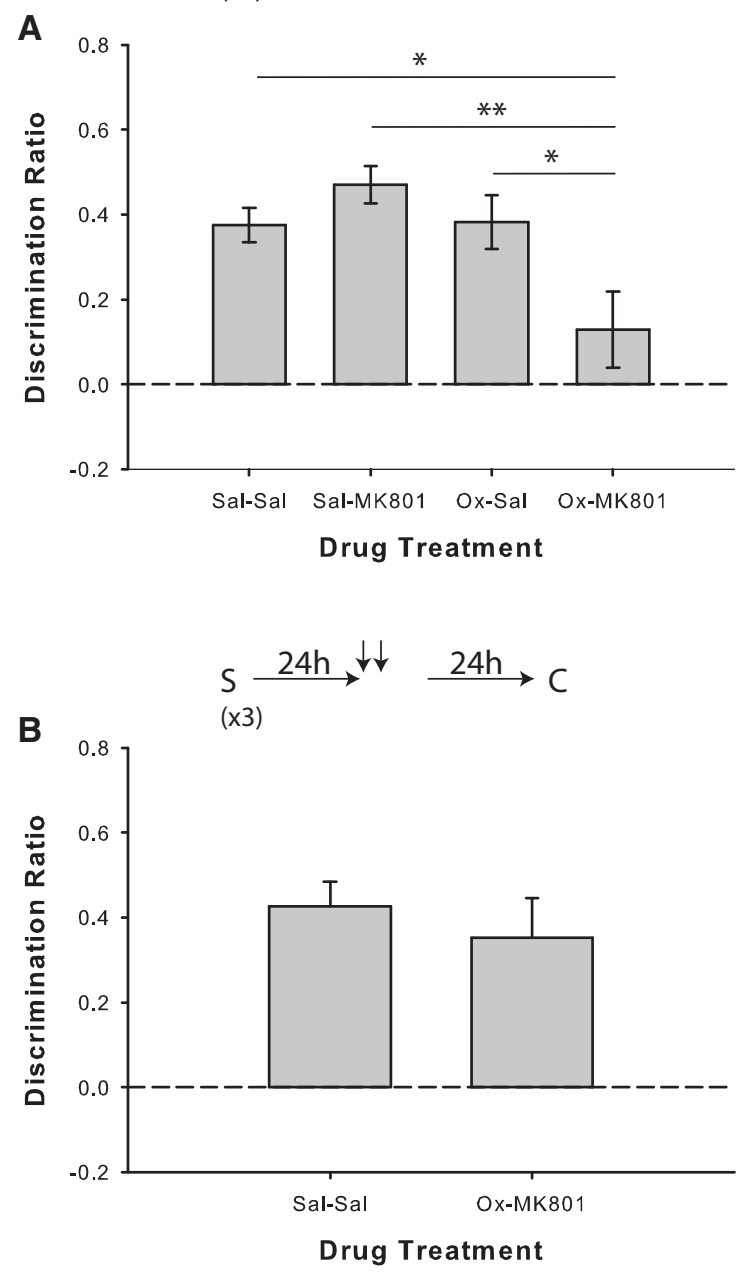

Figure 5. Muscarinic cholinergic receptor agonism with oxotremorine mimics novelty-induced destabilization of strongly encoded object memories. (A) Object recognition performance by rats in Experiment $4 \mathrm{a}(n=$ 20). Performance was not affected by the saline/MK-801 pairing when strongly encoded memories were reactivated in the absence of salient novelty; however, coadministration of oxotremorine (Ox) with MK-801 prior to reactivation produced a failure to discriminate between the novel and sample objects in the choice phase. Rats in all drug conditions except for Ox/MK-801 showed significant novel object preference, as indicated by separate one-sample $t$-tests versus chance $(0)$. (B) Experiment $4 \mathrm{~b}(n=8)$, in which the reactivation phase was omitted, confirmed that the impairment seen in the Ox/MK-801 condition was reactivationdependent. Rats treated with either a double injection of saline or oxotremorine plus MK-801 discriminated significantly above chance according to one-sample $t$-tests. Data are presented as average discrimination ratio \pm SEM. $\left(^{*}\right) P<0.05 ;\left({ }^{* *}\right) P<0.01$.

synthesis inhibitor anisomycin to assess the possibility that cholinergic activity within PRh could contribute to the systemic effects observed in Experiments 1-5. All rats included in the behavioral analyses for Experiments 6-8 had guide cannulas located bilaterally with injection needle tips terminating in PRh near the border between areas 35 and 36 (Burwell 2001); these placements were consistently located between 5.80 and 6.30 $\mathrm{mm}$ posterior to bregma (Fig. 7 presents cannula tip placements for Experiment $6 \mathrm{a}$; placements were similar for all subsequent PRh infusion experiments).
In Experiment 6a, intra-PRh anisomycin resulted in reconsolidation impairment similar to that seen with systemic MK-801, and prereactivation intra-PRh scopolamine appears to have blocked object memory destabilization, thereby preventing this deficit (Fig. 8). ANOVA revealed a significant drug effect $\left(F_{(3,21)}=5.2 ; P=0.008\right)$, and performance in the saline/anisomycin condition was significantly impaired relative to saline/saline $\left(t_{(7)}=3.04 ; \quad P=0.019\right), \quad$ scopolamine $/$ saline $\quad\left(t_{(7)}=3.48 ; \quad P=\right.$
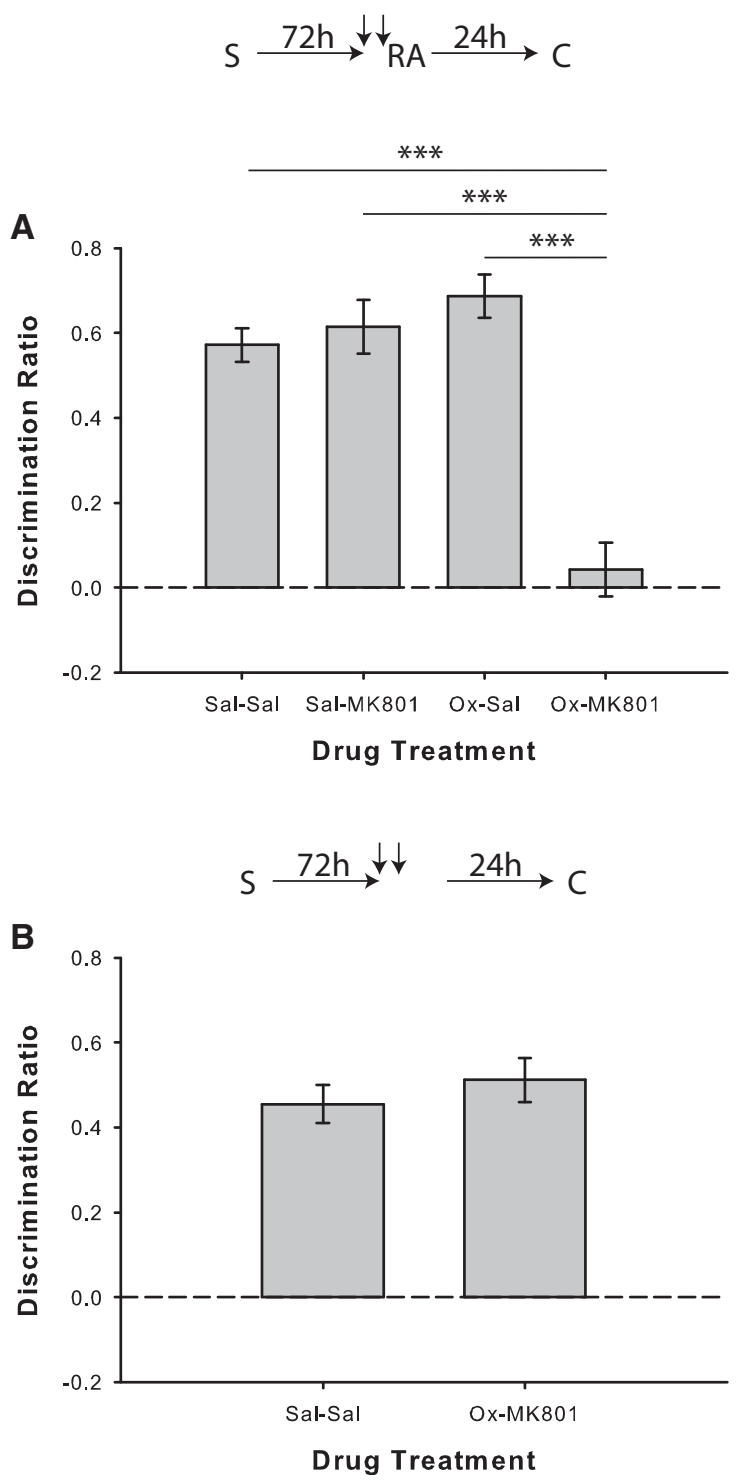

Figure 6. Muscarinic cholinergic receptor agonism with oxotremorine mimics novelty-induced destabilization of relatively remote object memories. (A) Object recognition performance by rats in Experiment $5 \mathrm{a}(n=12)$. There was no impairment in the saline/MK-801 condition when relatively remote memories were reactivated in the absence of salient novelty; however, coadministration of oxotremorine $(\mathrm{Ox})$ with MK-801 prior to reactivation did disrupt object recognition performance. Rats in all drug conditions except for Ox/MK-801 showed significant novel object preference in the choice phase, as indicated by separate one-sample $t$-tests versus chance (0). (B) Experiment $5 \mathrm{~b}(n=12)$, in which the reactivation phase was omitted, confirmed that the deficit shown in the oxotremorine/ MK-801 condition was reactivation-dependent. One-sample $t$-tests revealed that rats treated with either a double injection of saline or oxotremorine plus MK-801 discriminated significantly above chance. Data are presented as average discrimination ratio \pm SEM. $(* * *) P<0.001$. 


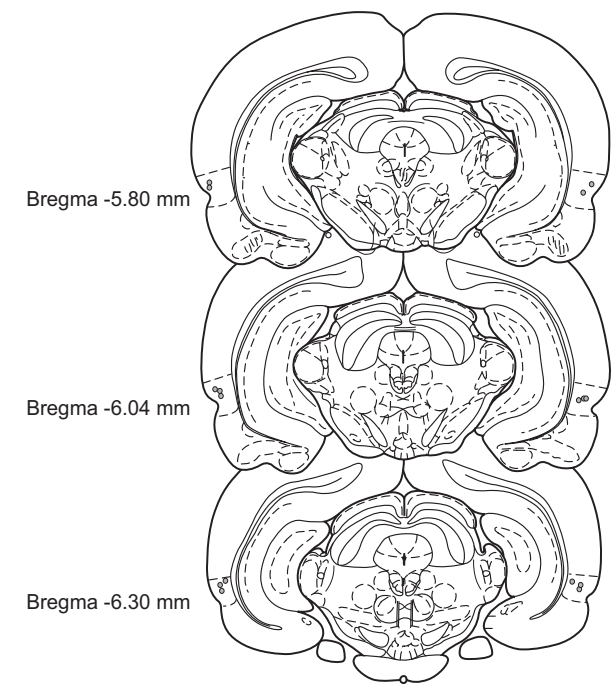

Figure 7. Schematic representation of the infusion needle tip placements from a typical group of rats with PRh implantations (Experiment $6 a, n=8$ ). These placements are representative of needle tip locations in all rats included in the behavioral analyses for the intra-PRh infusion experiments in the present study. Cannulas in PRh were consistently located between 5.80 and $6.30 \mathrm{~mm}$ posterior to bregma. Some needle tips overlap in the figure. Brain section illustrations modified from Paxinos and Watson (1998). Dashed lines surrounding placements approximate the borders of PRh as defined by Burwell (2001).

$0.01)$, and scopolamine/anisomycin $\left(t_{(7)}=2.64 ; P=0.03\right.$; onetailed test) conditions. Rats also showed significant novel object preference in all conditions (all $P<0.01$ ), except for saline/anisomycin $(P=0.738)$. We have previously demonstrated that the intra-PRh blockade of object memory destabilization is reactivation-dependent (Winters et al. 2011).

In Experiment 6b, intra-PRh infusions of anisomycin and scopolamine were paired immediately after the initial sample phase of the SOR task to test the possibility that scopolamine merely blocks the protein synthesis inhibition induced by anisomycin. Paired scopolamine and anisomycin, however, resulted in significant memory consolidation impairment relative to trials on which rats received paired saline infusions immediately after learning $\left(t_{(7)}=2.64 ; P=0.034\right.$; mean discrimination ratio \pm SEM: saline $/$ saline $=0.23 \pm 0.08$, scopolamine $/$ anisomycin $=$ $-0.14 \pm 0.12$; see Supplemental Fig. S1). Saline/saline trials were also associated with significant novelty preference $(P=0.03)$, whereas scopolamine/anisomycin pairing was not $(P=0.268)$. This finding suggests that the remediative effects of scopolamine in Experiment 6a were not the result of a general blockade of the actions of anisomycin on protein synthesis.

\section{Experiment 7: blockade of muscarinic receptors in perirhinal cortex prevents novelty-induced destabilization of relatively remote object memories}

Intra-PRh saline/anisomycin pairing resulted in reconsolidation impairment similar to that seen with systemic MK-801 when the floor insert was present during the reactivation of relatively remote object memories; also consistent with the systemic findings, intra-PRh scopolamine appears to have blocked novelty-induced object memory destabilization, thereby preventing the anisomycin-induced reconsolidation deficit (Fig. 9). ANOVA revealed a significant drug effect $\left(F_{(3,21)}=5.89 ; P=0.004\right)$, and performance in the saline/anisomycin condition was significantly impaired relative to saline/saline $\left(t_{(7)}=3.99 ; P=0.005\right)$, scopolamine/saline $\left(t_{(7)}=3.00 ; P=0.02\right.$; one-tailed test $)$, and scopolamine/anisomycin $\left(t_{(7)}=2.91 ; P=0.023\right.$; one-tailed test) conditions. Rats also showed significant novel object preference in all conditions (all $P<0.01)$, except for saline/anisomycin $(P=0.477)$. There was also a significant drug effect on the duration of the reactivation phase $\left(F_{(3,21)}=3.77 ; P=0.026\right)$, with rats taking longer to explore in the scopolamine/saline $\left(t_{(7)}=3.24 ; P=0.014\right)$ and scopolamine/anisomycin $\left(t_{(7)}=2.48 ; P=0.042\right)$ conditions when compared with saline/saline trials (see Supplemental Table S1); total object exploration in the reactivation phase, however, did not differ between drug conditions $\left(F_{(3,21)}=0.95 ; P=0.434\right)$.

\section{Experiment 8: activation of cholinergic receptors in perirhinal cortex mimics novelty-induced destabilization of relatively remote object memories}

Similar to the results seen with systemic MK-801, intra-PRh anisomycin failed to disrupt object memory reconsolidation when $48 \mathrm{~h}$ passed between the sample and (standard) reactivation phases. However, like with systemic oxotremorine, agonism of cholinergic receptors by intra-PRh carbachol apparently prompted memory destabilization in this condition, leading to anisomycininduced memory impairment (Fig. 10). ANOVA indicated a significant drug effect $\left(F_{(3,24)}=18.49 ; P<0.001\right)$, and performance in the carbachol/anisomycin condition was significantly impaired relative to saline/saline $\left(t_{(8)}=5.28 ; P<0.001\right)$, saline/anisomycin $\left(t_{(8)}=6.78 ; P<0.001\right)$, and carbachol/saline $\left(t_{(8)}=5.68 ; P<\right.$ $0.001)$ conditions. Rats also showed significant novel object preference in all conditions (all $P<0.01$ ), except for saline/anisomycin $(P=0.746)$. Although there was no difference in terms of sample or reactivation exploration values or durations, there was a significant drug effect for first-minute total object exploration in the choice phase $\left(F_{(3,24)}=6.32 ; P=0.003\right)$, as the carba$\mathrm{chol} /$ anisomycin condition was associated with significantly higher choice phase exploration than saline/saline $\left(t_{(8)}=4.37\right.$; $P=0.002)$ or saline/anisomycin $\left(t_{(8)}=3.63 ; P<0.007\right.$; see Supplemental Table S1). Considering that the drug was administered over $24 \mathrm{~h}$ prior to the choice phase, as well as the fact that there was no such difference between carbachol/saline and carbachol/anisomycin conditions, this effect seems an unlikely explanation for the apparent memory deficit.
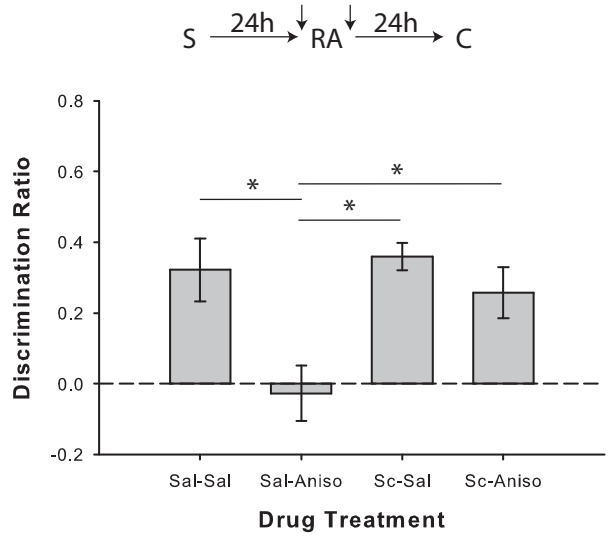

Figure 8. Muscarinic cholinergic receptor antagonism in PRh prevents destabilization of object memories. Object recognition performance by rats in Experiment $6 \mathrm{a}(n=8)$. Prereactivation intra-PRh infusion of scopolamine (Sc) blocked the typical post-reactivation anisomycin-induced object memory reconsolidation impairment. Separate one-sample $t$-tests versus chance $(0)$ indicated that rats in all drug conditions except for saline/anisomycin showed significant preference for the novel object in the choice phase. Data are presented as average discrimination ratio \pm SEM. $\left(^{*}\right) P<0.05$. 


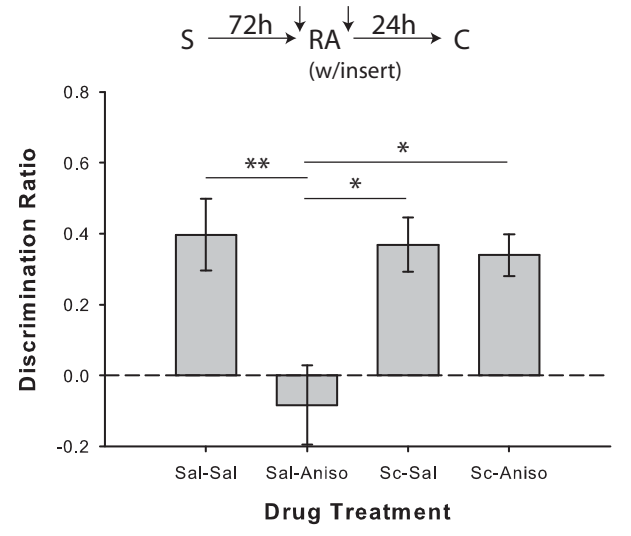

Figure 9. Intra-PRh scopolamine prevents novelty-induced destabilization of relatively remote object memories. Object recognition performance by rats in Experiment $7(n=8)$. Prereactivation infusion of scopolamine (Sc) blocked the post-reactivation anisomycin-induced memory reconsolidation impairment observed when relatively remote object memories were reactivated in the presence of a salient novel contextual cue ("insert"). Separate one-sample $t$-tests versus chance $(0)$ indicated that rats in all drug conditions except for saline/anisomycin showed significant preference for the novel object in the choice phase. Data are presented as average discrimination ratio \pm SEM. $\left({ }^{*}\right) P<0.05 ;(* *) P<0.01$.

In Experiment 8b, coadministration of carbachol and anisomycin $48 \mathrm{~h}$ after the sample phase did not affect object recognition memory when the reactivation phase was omitted (pairedsamples $t$-test versus saline/saline: $t_{(6)}=0.195 ; P=0.852$; Mean discrimination ratio \pm SEM: saline/saline $=0.49 \pm 0.04$, carba$\mathrm{chol} /$ anisomycin $=0.48 \pm 0.04$; see Supplemental Fig. S2), and rats showed significant novel object preference on both trial types (both $P<0.01$ ).

\section{Discussion}

Here we show for the first time that blockade of muscarinic cholinergic receptors, systemically or within PRh, appears to prevent destabilization of object memories; this effect was revealed through various interactions of cholinergic agonist and antagonist drugs with the typical reconsolidation-blocking effects of the NMDA receptor antagonist MK-801 or the protein synthesis inhibitor anisomycin. The intra-PRh result is consistent with numerous studies implicating PRh in object memory processing, including reconsolidation (Buckley 2005; Murray et al. 2007; Winters et al. 2008, 2011; Brown et al. 2012; Balderas et al. 2013). Furthermore, stimulating muscarinic receptors during memory reactivation with systemic or intra-PRh delivery of muscarinic receptor agonists mimicked the memory destabilizing effects of salient novelty; when strongly encoded or relatively remote memories were reactivated in the absence of the contextual change, they were not destabilized unless oxotremorine or carbachol was administered prior to the reactivation phase. These results highlight the importance of muscarinic receptor activation in object memory destabilization and have important implications for the role of ACh in the memory updating functions of reconsolidation.

We predicted a key role for cholinergic transmission in memory destabilization because of the common finding that reconsolidation is prompted most reliably when novel information is available during the reactivation episode (Rodriguez-Ortiz et al. 2005; Morris et al. 2006; Rossato et al. 2007; Winters et al. 2009; Forcato et al. 2010; Sevenster et al. 2013). Indeed, ACh has long been implicated in cognitive functions linked to new learning
(Sarter and Bruno 1997; Hasselmo and McGaughy 2004), and in vivo microdialysis studies demonstrate enhanced ACh release in various brain regions when animals explore novel environments or objects (Tang and Aigner 1996; Aloisi et al. 1997; Giovannini et al. 2001; Ihalainen et al. 2010) or are otherwise aroused (Nilsson et al. 1990; Inglis and Fibiger 1995) or attentionally taxed (Passetti et al. 2000). Moreover, the amnesic effects of scopolamine are typically observed when the drug is administered prior to new learning and not before memory testing (Aigner et al. 1991; Tang et al. 1997; Warburton et al. 2003; Winters et al. 2006). Such findings suggest that, rather than blocking memory retrieval per se, the effects of scopolamine in the current study were more likely the result of a direct effect on the destabilization process; indeed, even if scopolamine were to block memory retrieval, Balderas et al. (2013) have recently demonstrated that object memory retrieval and reconsolidation are apparently independent processes, implying that the pattern of effects observed herein are more likely the result of influence on memory destabilization per se. Past findings indicate an important role for cholinergic transmission in novel information encoding. The acute sensitivity of the cholinergic system to novel stimulation thus provides it with characteristics consistent with those required of a signaling mechanism for the putative memory updating functions of the reconsolidation process.

The present results strongly suggest that cholinergic transmission via muscarinic receptors in PRh is, indeed, an important cellular trigger for object memory destabilization, without which reconsolidation-and thus memory updating-may not occur; it should be noted, however, that carbachol also activates nicotinic receptors, so nicotinic involvement in the intra-PRh carbacholinduced memory destabilization effects cannot be ruled out. The present findings also support the notion that the reactivation phase is not merely acting as a second sample phase in this paradigm. We and others have consistently shown that scopolamine administered prior to the sample phase causes robust learning impairments (Warburton et al. 2003; Winters et al. 2006, 2007); however, prereactivation scopolamine in the present study caused no

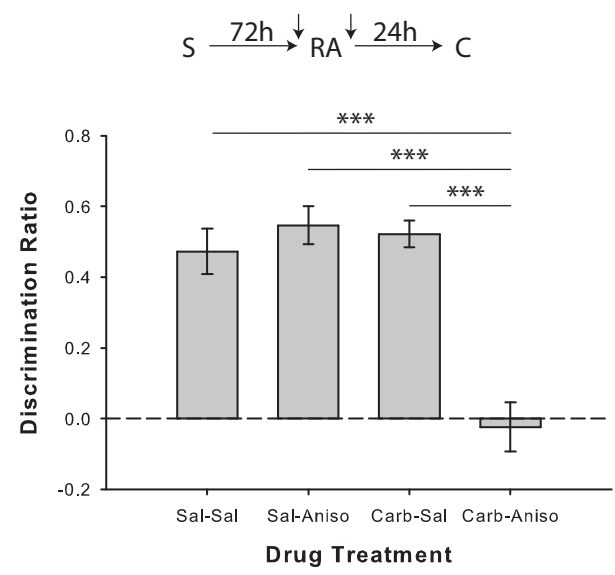

Figure 10. Cholinergic receptor agonism in PRh mimics the object memory destabilizing effects of reactivation novelty. Object recognition performance by rats in Experiment $8 \mathrm{a}(n=9)$. Prereactivation infusion of the cholinomimetic carbachol prompted apparent object memory destabilization and blockade by anisomycin of reconsolidation following reactivation without the salient novel contextual cue. Neither carbachol nor anisomycin affected object recognition performance when paired with saline. Separate one-sample $t$-tests versus chance $(0)$ indicated that rats in all drug conditions except for carbachol/anisomycin showed significant preference for the novel object in the choice phase. Data are presented as average discrimination ratio \pm SEM. $\left.{ }^{* * *}\right) P<0.001$. 
apparent detrimental effects on learning when given with saline, and, if anything, produced quite the opposite effect when coadministered with MK-801 or anisomycin. Moreover, the results of Experiment 1c demonstrate that scopolamine does not affect memory retrieval during the reactivation phase; rather, its effect appears to be more specifically linked to reactivation-induced memory destabilization. The bidirectional nature of the current results argues strongly for a cholinergic role in object memory destabilization, and in a paradigm that requires explicit novelty at reactivation to render memories labile. We also observed scopolamine blockade of destabilization in the "standard" SOR reconsolidation task, in which the salient contextual change is not necessary to prompt reconsolidation. We have previously argued, however, that relatively weakly encoded object memories may become destabilized upon reactivation in this paradigm because the animals have not encoded a complete object representation (Winters et al. 2009). Thus, in the "standard" version of the task, additional memory updating opportunities may be available in the reactivation phase (Lee 2009), prompting sufficient novelty-induced $\mathrm{ACh}$ release to destabilize the memory trace. More strongly encoded and relatively remote object memories clearly undergo additional processing, necessitating more explicit updating opportunities in order to be destabilized during the reactivation phase. Nonetheless, ACh may be playing the same triggering role in all three cases of putative memory updating.

An important topic for future investigation regards the intracellular mechanisms involved in ACh-induced memory destabilization. Activation of M1 muscarinic receptors can increase post-synaptic insertion of AMPA receptors (Fernández de Sevilla et al. 2008), providing a potential mechanistic connection between the effects of cholinergic transmission on object memory destabilization and the demonstrated requirement of AMPA receptor exchange for fear memory destabilization (Hong et al. 2013). Questions for future research concern whether a similar process occurs within PRh for object memories and the nature of muscarinic receptor subtype involvement in the effects demonstrated here. Moreover, NMDA receptors and ubiquitin proteasome system (UPS)-mediated synaptic protein degradation have both been implicated in destabilization of certain forms of memory (Ben Mamou et al. 2006; Lee et al. 2008; Choi et al. 2010; Milton et al. 2013). It will be interesting to see whether the cholinergic influence demonstrated here interacts with any of these previously established mechanisms of memory destabilization. For example, muscarinic receptor activity could directly promote UPS activation; alternatively the UPS may be stimulated indirectly via muscarinic enhancement of NMDA receptor activity. Either way, the demonstrated novelty-induced destabilization of object memories could result from muscarinic receptor-induced activation of intracellular changes linked to degradation of synaptic proteins, a process that likely explains the need for protein synthesis to reconsolidate memories following sufficient memory reactivation.

It will be important to evaluate the ability of cholinergic activity in other brain regions to influence destabilization of memories for objects and other types of information. Nonetheless, the bidirectional effects reported here provide particularly strong evidence for a crucial role of cholinergic transmission within PRh in object memory destabilization, most likely under conditions favoring memory updating; the attention-capture or arousal associated with salient novel stimuli present during object memory reactivation may increase cholinergic transmission within PRh, triggering a cascade of cellular changes necessary for memory trace destabilization. Surprisingly, study of the involvement of ACh in the memory reconsolidation process has been relatively lacking compared with other neural systems and cellular mecha- nisms. Indeed, whereas only a few studies have even examined the role of cholinergic transmission in post-reactivation memory restabilization, the effects we report in the current study, implicating ACh in the initial "destabilization" of memories, is unprecedented. Additional research is merited to clarify the specific mechanisms underlying this neuromodulatory cholinergic function.

\section{Materials and Methods}

\section{Subjects}

The subjects were male Long-Evans rats weighing between 280 and $300 \mathrm{~g}$ at the start of each experiment. New sets of rats were used for each experiment. The majority of experiments used $10-12$ rats, with a minimum of 7 rats in one experiment; our previous work has indicated that a power of 0.80 can be achieved using a minimum sample size of 6 rats $(\alpha=0.05)$. Rats were housed in pairs on a reverse light/dark cycle (lights off 8:00-20:00), and testing took place during the dark phase. Each rat received $20 \mathrm{~g}$ of rodent chow in the afternoon, post-testing, in order to maintain $85 \%-90 \%$ free-feeding weight. Although object recognition tasks do not necessarily rely on food seeking for their performance, it has been consistently found that object exploratory behavior is more robust when rats are food restricted during testing (Ennaceur 2010). Water was freely available throughout the experiments, except when rats were in the testing apparatus. All procedures followed guidelines established by the Canadian Council on Animal Care and were approved by the Animal Care Committee at the University of Guelph.

\section{Drugs}

The NMDA receptor antagonist, MK-801 (Sigma), was administered at a concentration of $0.1 \mathrm{mg} / \mathrm{kg}$ in all systemic drug experiments (Experiments 1-5). Experiments 1-3 involved administration of the muscarinic acetylcholine receptor antagonist scopolamine (Sigma) at a concentration of $0.3 \mathrm{mg} / \mathrm{kg}$. The nonselective muscarinic acetylcholine receptor agonist oxotremorine (Sigma) was administered at a concentration of $0.1 \mathrm{mg} / \mathrm{kg}$ in Experiments 4 and 5. All systemic drugs were administered via intraperitoneal (ip) injection $20 \mathrm{~min}$ prior to the reactivation phase or at an approximately equivalent time following the sample phase in experiments not involving explicit reactivation. Vehicle control in all systemic drug experiments was $0.9 \%$ physiological saline $(\mathrm{pH}=7.4)$. For Experiments $6-8$, the protein synthesis inhibitor anisomycin (Sigma) was initially dissolved in $1 \mathrm{~N} \mathrm{HCl}$. The $\mathrm{pH}$ of the solution was then adjusted to 7.4 by addition of $\mathrm{NaOH}$, and the final concentration was adjusted to $100 \mu \mathrm{g} / \mu \mathrm{L}$ by adding $0.9 \%$ physiological saline. Rats received bilateral infusions of either $0.9 \%$ physiological saline or anisomycin delivered to the perirhinal cortex (PRh) on a given trial, immediately following the reactivation phase. For Experiments 6 and 7, postreactivation anisomycin infusions were paired with bilateral intra-PRh infusions of either physiological saline or scopolamine [scopolamine hydrobromide (Sigma), dissolved in physiological saline at a concentration of $20 \mu \mathrm{g} / \mu \mathrm{L}] 15 \mathrm{~min}$ prior to the reactivation phase. For Experiment 8, prereactivation bilateral intra$\mathrm{PRh}$ infusions of the cholinergic receptor agonist carbachol (Sigma; dissolved in physiological saline at a concentration of $0.25 \mu \mathrm{g} / \mu \mathrm{L}$ ) were paired with post-reactivation anisomycin. Rats were gently restrained by the experimenter throughout the infusion process. The dummy cannulas were removed, and the 28-gauge infusion cannulas, which were cut to extend $1 \mathrm{~mm}$ beyond the tip of the guide cannulas, were inserted. Bilateral infusions were conducted simultaneously using two 1- $\mu$ L Hamilton syringes, which were connected to the infusion cannulas by propylene tubing. The syringes were driven by a Harvard Apparatus precision syringe pump, which delivered $1 \mu \mathrm{L}$ to each hemisphere over 2 min. The infusion cannulas were left in place for an additional $1.5 \mathrm{~min}$ to allow for diffusion of the infusate. The 
infusion cannulas were then removed, and the dummy cannulas re-inserted.

All experiments were run with drug as a within-subjects factor, and rats received counterbalanced administration of the various drug conditions over multiple trials (see below). All drug administration took place in a preparation room separate from the behavioral testing area and was done by an experimenter blind to the drug identities. Rats were returned to their home cages following injections or infusions until the reactivation or choice phase.

\section{Surgical procedures}

For Experiments 6-8, rats were implanted bilaterally in PRh with 22-gauge indwelling guide cannulas (Plastics1; HRS Scientific, QC) according to the following procedure. Rats were deeply anesthetized with isofluorane inhalation anesthetic (Benson Medical Industries, Markham, Ontario). Animals also received a systemic (sc) injection of the analgesic meloxicam $(5 \mathrm{mg} / \mathrm{mL}$; Boehringer Ingelheim, Burlington, Ontario) prior to surgery. They were then placed in a stereotaxic frame (Kopf Instruments, Tujunga, $\mathrm{CA}$ ) with the incisor bar set to $-3.3 \mathrm{~mm}$. The scalp was cut and retracted to expose the skull, and holes were drilled directly above the target region. The guide cannulas were implanted according to the following coordinates, measured relative to the skull at bregma (Paxinos and Watson 1998): anteroposterior $-5.5 \mathrm{~mm}$, lateral $\pm 6.6 \mathrm{~mm}$, dorsoventral $-6.5 \mathrm{~mm}$. The cannulas were secured to the skull using four jeweler screws and dental acrylic. Dummy cannulas cut to extend $1.1 \mathrm{~mm}$ beyond the tip of the guide cannulas and with an outer diameter of $0.36 \mathrm{~mm}$ were inserted into the guides and remained there except during infusions. At the completion of surgery, the skin was sutured, and animals recovered in cages on heat pads for $1-2 \mathrm{~h}$ before being returned to their home cages. Rats were allowed to recover in their home cages for at least $7 \mathrm{~d}$ prior to the beginning of behavioral testing.

\section{Apparatus}

A Y-shaped apparatus was used for all stages of the spontaneous object recognition task, as previously described (Winters et al. 2004; Forwood et al. 2005). The apparatus was constructed entirely of white Plexiglas with walls of $40 \mathrm{~cm}$ in height and each of the three arms measuring $27 \mathrm{~cm}$ in length and $10 \mathrm{~cm}$ in width. The start arm was denoted by a guillotine door located $18 \mathrm{~cm}$ from the rear of the arm. When closed, this door created a $10 \times 18 \mathrm{~cm}$ start box enclosure in which each rat was placed prior to each phase of every trial. A video camera, mounted above the apparatus on a tripod, was used to document all trials. Duplicate copies of objects varying in material (ceramic, metal, plastic, and glass), height (10-20 $\mathrm{cm})$, and other visual and tactile features were obtained. Reusable adhesive putty was used to fix the objects to the floor of the apparatus at the ends of the two exploration arms to prevent displacement during exploration. Objects were wiped down with 50\% ethanol immediately after each phase in which they were used. The apparatus itself was never cleaned beyond wiping the floor and walls with a dry paper towel between each rat, as needed.

\section{General procedure}

Each experiment followed the same general procedure. Specific experimental manipulations are outlined below. All rats were habituated to the empty Y-shaped apparatus in two consecutive daily sessions. Each rat was individually brought to the experiment room in a transport cage and given a physiological saline injection (0.3 mL, ip; Experiments 1-5) or a "mock" intra-PRh infusion (no liquid; Experiments 6-8). Immediately following the injection/ infusion, the rat was taken to the Y-shaped apparatus, placed in the start box, and released into the main exploration area for 5 min.

Each trial consisted of three phases (sample, reactivation, and choice) with a minimum retention interval (sample-tochoice) of $48 \mathrm{~h}$. This was achieved by a minimum $24 \mathrm{~h}$ delay be- tween each of the consecutive phases. Specific manipulations for each experiment are outlined below. A different object pair was used for each rat and for each trial such that no rat encountered the same object pair twice. The order of exposure to each pair, the designated sample and novel object within each pair, and which arm of the apparatus (left or right) would contain the novel object during the choice phase were all counterbalanced for each experiment.

For the sample phase, two identical objects $\left(\mathrm{A}_{1}\right.$ and $\left.\mathrm{A}_{2}\right)$ were placed at the distal end of each of the exploration arms. Each rat was individually transported to the testing room and placed in the start box. The guillotine door was opened to allow the rat access to the exploration arms and was then lowered to prevent reentry of the start box. Once the rat had completely exited the start box, the sample phase began. The experimenter, viewing the rat on a screen captured by the video camera, scored the time spent exploring each object. Exploration was defined as directing the nose toward an object at a distance of $<2 \mathrm{~cm}$ and/or direct contact of the object with the rat's nose. The sample phase lasted until the rat had completed $30 \mathrm{sec}$ of exploration or after a total of $3 \mathrm{~min}$ had elapsed, whichever happened first. The rat was then removed from the apparatus and returned to its cage in the housing room. This method of requiring a minimal level of sample exploration aims to ensure that all animals study the sample objects for the same amount of time, which contrasts with the common procedure of enforcing a set length of time for the sample phase. Many other groups have used the current technique in their work, and we favor this approach, especially in the context of the current study for which precise control of sample and reactivation object exploration was sought.

For the reactivation phase, the same object pair $\left(\mathrm{A}_{1}\right.$ and $\left.\mathrm{A}_{2}\right)$ was positioned in the exploration arms. Each rat was individually transported to the testing room and was administered two ip injections in quick succession or a single intra-PRh infusion (details for each experiment given below). The experimenter was always blind to the identity of the drugs being administered; this was accomplished by having a second researcher code the drugs as $\mathrm{A}, \mathrm{B}, \mathrm{C}$, etc. The rat then remained in its home cage for $20 \mathrm{~min}$ (15 min for intra-PRh infusions), after which time it was returned to the testing room for the reactivation phase (except for "no reactivation" control experiments, see below). This phase was carried out identically to the sample phase, except that it ended when the rat completed 10 sec of object exploration or a total of 2 min elapsed. The rat was then removed from the apparatus and returned to its cage in the housing room for $24 \mathrm{~h}$.

For the choice phase, the Y-shaped apparatus was set up with a sample ("familiar") object $\left(\mathrm{A}_{1}\right.$ or $\left.\mathrm{A}_{2}\right)$ in one arm and a novel object (B) in the other arm. The time spent exploring the novel and sample objects was recorded for $1 \mathrm{~min}$. The use of a constant scoring period for the choice phase is an established procedure, as robust recognition scores can be collected with a range of object exploration levels; we used an exclusion criterion of total object exploration $<4 \mathrm{sec}$, but this was not required for any trials in the current study. The choice object exploration data were used to calculate a discrimination ratio, [i.e., novel object exploration - familiar object exploration/(novel object exploration + familiar object exploration)], for each object recognition trial. This measure takes into account individual differences in the total amount of exploration time. Normal rats tend to explore the novel object more than the familiar sample object in this spontaneous object recognition paradigm (Ennaceur and Delacour 1988). In addition to real-time scoring of object exploration in each phase of testing by an observer blind to experimental conditions, all trials were video recorded and rescored offline by the original experimenter and an additional researcher. These videos were used to calculate inter-rater reliability scores, which were found to be highly significant for sample and choice phase scoring (Pearson $r$ ranging from 0.7 to 0.9 ).

\section{Experiment la}

Experiment $1 \mathrm{a}$ was conducted to assess the effect of muscarinic receptor antagonism during the reactivation phase in our 
"standard" SOR reconsolidation paradigm. 0.9\% physiological saline, scopolamine, and MK- 801 were used in this experiment in the dosages previously indicated. The following combinations of systemic drugs were administered prior to the reactivation phase: saline/saline, saline/MK-801, scopolamine/saline, scopolamine/MK-801. Twelve rats were used for this experiment, and each was tested under all four drug conditions. All three phases (sample, reactivation, and choice) were conducted as described above, except the delay between sample and reactivation was 24 $\mathrm{h}$. The sample-to-choice retention interval was therefore $48 \mathrm{~h}$.

\section{Experiment $\mathrm{lb}$}

Experiment $1 \mathrm{~b}$ was conducted to confirm, as previously shown (Winters et al. 2009), that the amnesic effect of MK-801 in the standard SOR reconsolidation paradigm was reactivation-dependent. Experiment 1b was run exactly as Experiment 1a, except that the reactivation phase was omitted, and rats were merely injected with one of the four drug combinations $\sim 24 \mathrm{~h}$ after the sample phase; they were immediately returned to their home cages for $24 \mathrm{~h}$ prior to the choice phase. Twelve rats were used for this experiment, and each was tested under all four drug conditions.

\section{Experiment 1c}

Experiment 1c was designed to ensure that scopolamine did not prevent the MK-801-induced deficit by blocking memory retrieval during the reactivation phase. The same parameters were used as in Experiment 1a, except that a novel object replaced one of the familiar objects in the reactivation phase (A and $\mathrm{B}$ ) and a different novel object was used during the choice phase (A and C). This allowed us to assess object recognition during the reactivation phase and determine if scopolamine was indeed influencing memory retrieval per se. Twelve rats were used for this experiment, and each was tested under all four drug conditions.

\section{Experiment 2a}

Experiment 2a tested the hypothesis that muscarinic receptor antagonism would prevent the novelty-induced destabilization of otherwise resistant, strongly encoded object memories. We therefore used the same drug combinations as in Experiment $1 \mathrm{a}$, but ran the "stronger encoding" version of our SOR reconsolidation paradigm, as previously described (Winters et al. 2009). Stronger encoding was encouraged by having rats $(n=10)$ explore the same sample objects over three separate sample phases on the same day. The interval between sample phases was $\sim 1 \mathrm{~h}$. Each sample phase was run identically, as described above. As in Experiment $1 \mathrm{a}$, the reactivation phase occurred $24 \mathrm{~h}$ after the sample phase; however, in Experiment 2a we used the "novel" reactivation condition. In the novel reactivation condition, the sample objects were represented to the rats in the same Y-shaped apparatus, but with one significant contextual modification. An insert constructed of white foam board and covered in no-slip rubber padding was placed inside the apparatus. The insert was $10 \mathrm{~cm}$ wide, and extended $38 \mathrm{~cm}$ from inside the start box into the exploration area. The floor insert did not extend into the arms containing the objects, but covered the entire "middle stem" of the Y-shaped apparatus, extending beyond the start box into the exploratory area. All other experimental details were identical to Experiment 1a.

\section{Experiment $2 b$}

Experiment $2 \mathrm{~b}$ was run to confirm the necessity of the novel insert for destabilizing the more strongly encoded object memories induced in Experiment 2a. All procedures were identical to those for Experiment 2a, except that the reactivation phase was run in the absence of the novel floor insert (i.e., the Y-shaped apparatus was unchanged from the sample phase). Ten rats were tested.

\section{Experiment 3a}

Experiment 3a tested the hypothesis that muscarinic receptor antagonism would prevent the novelty-induced destabilization of otherwise resistant, relatively remote object memories. We used the same drug combinations as in Experiment 1a, but ran the "older object memory" version of our SOR reconsolidation paradigm, as previously described (Winters et al. 2009). This involved merely waiting an additional $24 \mathrm{~h}$ after the sample phase before running the reactivation phase (for a total of $48 \mathrm{~h}$ between sample and reactivation). Memory reactivation was conducted in the presence of the novel floor insert, as described for Experiment 2a. All other experimental details were identical to Experiment $1 \mathrm{a}$. Twelve rats were tested. The sample-to-choice retention interval was $72 \mathrm{~h}$.

\section{Experiment $3 b$}

Experiment $3 b$ was run to confirm the necessity of the novel insert for destabilizing the relatively remote object memories assessed in Experiment 3a. All procedures were identical to those in Experiment $3 a$, except that the reactivation phase was run in the absence of the novel floor insert. Ten rats were tested.

\section{Experiment $4 a$}

Experiment 4a assessed the hypothesis that muscarinic receptor agonism would mimic the memory destabilizing effects of explicit novel information (i.e., floor insert) during the reactivation phase on strongly encoded object memories. Accordingly, rats $(n=20)$ were tested with the following systemic drug combinations administered prior to the reactivation phase: saline/saline, saline/ MK-801, oxotremorine/saline, oxotremorine/MK-801. All other experimental details were the same as in Experiment 2a, except that the floor insert was not used during the reactivation phase.

\section{Experiment $4 \mathrm{~b}$}

Experiment $4 \mathrm{~b}$ assessed the necessity of the reactivation phase for the effects observed in Experiment 4a. Eight rats were run on two separate counterbalanced trials, one in which saline/saline was administered and one in which oxotremorine/MK-801 was given. All other procedures were identical to Experiment 4a, except that the reactivation phase was omitted; drugs were administered $\sim 24$ $\mathrm{h}$ after the last sample phase and $24 \mathrm{~h}$ prior to the choice phase.

\section{Experiment 5a}

Experiment 5a tested the hypothesis that muscarinic receptor activation would mimic the memory destabilizing effects of explicit novel information during the reactivation phase on relatively remote object memories. Twelve rats were tested with the same systemic drug combinations as those used in Experiment $4 \mathrm{a}$ administered prior to the reactivation phase. All other experimental details were the same as in Experiment 3a, except that the floor insert was not used during the reactivation phase.

\section{Experiment $5 b$}

Experiment $5 \mathrm{~b}$ assessed the necessity of the reactivation phase for the effects observed in Experiment 5a. Twelve rats were run on two separate counterbalanced trials, one in which saline/saline was administered and one in which oxotremorine/MK-801 was given. All other procedures were identical to Experiment 5a, except that the reactivation phase was omitted; drugs were administered $\sim 48$ $\mathrm{h}$ after the last sample phase and $24 \mathrm{~h}$ prior to the choice phase.

\section{Experiment 6a}

Experiment 6 a investigated the necessity of muscarinic receptor activation within PRh for cholinergic regulation of object memory destabilization using the "standard" SOR reconsolidation procedure. Eight rats were implanted with bilateral cannulas for drug delivery into PRh. Behavioral procedures were identical to those used in Experiment 1a. The following intra-PRh drug 
combinations were administered, with the first drug given $15 \mathrm{~min}$ prior to the reactivation phase and the second infused immediately after the reactivation phase: saline/saline, saline/anisomycin, scopolamine/saline, scopolamine/anisomycin.

\section{Experiment $6 \mathrm{~b}$}

Experiment $6 \mathrm{~b}$ tested the possibility that scopolamine directly interacts with anisomycin to attenuate the latter's inhibitory effect on object memory consolidation; this was done to rule out a direct effect of scopolamine on the amnesic mechanism of anisomycin. Eight rats were tested for long-term object recognition memory using the SOR task without a reactivation phase. That is, rats experienced the sample and choice phases as described, separated by a 24 -h retention delay. There were two drug conditions, which were tested in a counterbalanced fashion in all rats: (1) saline/saline; (2) scopolamine/saline. All infusions were administered bilaterally into PRh immediately after the sample phase to assess effects on memory consolidation.

\section{Experiment 7}

Experiment 7 assessed the necessity of muscarinic receptor activation within PRh for cholinergic regulation of relatively remote object memory destabilization. Eight rats were implanted with bilateral cannulas for delivery of substances into PRh. Behavioral procedures were identical to those used in Experiment 3a. The following intra-PRh drug combinations were administered, with the first drug given 15 min prior to the reactivation phase and the second infused immediately after the reactivation phase: saline/saline, saline/anisomycin, scopolamine/saline, scopolamine/anisomycin.

\section{Experiment 8a}

Experiment 8a investigated the ability of cholinergic receptor agonism within PRh to provoke destabilization of relatively remote object memories in the absence of salient novelty during the reactivation phase. The agonist carbachol was used to stimulate cholinergic activity in PRh; earlier experiments were attempted with various doses of intra-PRh oxotremorine, but this procedure consistently produced seizure activity. Nine naïve rats were used for this experiment. Behavioral procedures were the same as in Experiment 3a, except that the floor insert was not used during the reactivation phase. The following intra-PRh drug combinations were administered, with the first drug given 15 min prior to the reactivation phase and the second infused immediately after the reactivation phase: saline/saline, saline/anisomycin, carbachol/saline, carbachol/anisomycin.

\section{Experiment 8b}

Experiment $8 \mathrm{~b}$ assessed the necessity of the reactivation phase for the effects observed in Experiment 8a. Seven rats were run on two separate counterbalanced trials, one in which saline/saline was administered and one in which carbachol/anisomycin was given. All other procedures were identical to Experiment 8a, except that the reactivation phase was omitted; drugs were administered $\sim 48$ $\mathrm{h}$ after the last sample phase and $24 \mathrm{~h}$ prior to the choice phase.

\section{Histology}

Following behavioral testing in Experiments 6-8, rats were anesthetized by intraperitoneal injection of $2 \mathrm{~mL}$ of Euthansol (340 $\mathrm{mg} / \mathrm{mL}$; Schering Canada Inc., Quebec) and perfused transcardially with $100 \mathrm{~mL}$ of phosphate buffered saline (PBS; pH 7.4), followed by $250 \mathrm{~mL}$ of $4 \%$ neutral buffered formalin (pH 7.4; EMD). The brains were removed, post-fixed in $4 \%$ formalin at $4^{\circ} \mathrm{C}$ for at least $24 \mathrm{~h}$ and then immersed in 20\% sucrose in PBS until they sank. A cryostat was used to cut coronal sections $(60 \mu \mathrm{m})$ through the extent of PRh, and every fifth section was mounted on a gelatin-coated glass slide and stained with cresyl violet. Slides were examined under a light microscope to verify the cannula placements.

\section{Data analysis}

Two variables for each phase of behavioral testing were analyzed: total sample object exploration and total sample phase duration; total reactivation object exploration and total reactivation phase duration; and total choice object exploration and discrimination ratio in the choice phase [novel object exploration - familiar object exploration/(novel object exploration + familiar object exploration)]. Total object exploration and duration of each phase were analyzed as control measures to rule out preexisting or drug-induced differences in exploratory behavior. Means were analyzed using one-way repeated-measures ANOVAs or pairedsamples $t$-tests (Experiments $4 \mathrm{~b}, 5 \mathrm{~b}, 6 \mathrm{~b}$, and $8 \mathrm{~b}$ ). Discrimination ratio means were also analyzed using one-sample $t$-tests comparing the values to 0 (indicating no object preference, i.e., "chance" performance). All statistical analyses were conducted using SPSS with a significance level of $\alpha=0.05$. For post hoc $t$-tests exploring significant main effects of drug condition, significance levels were adjusted using Bonferroni correction.

\section{Acknowledgments}

This research was supported by a National Sciences and Engineering Research Council (NSERC) of Canada Discovery Grant to B.D.W. and an Ontario Graduate Scholarship to D.L.J.

\section{References}

Aigner TG, Walker DL, Mishkin M. 1991. Comparison of the effects of scopolamine administered before and after acquisition in a test of visual recognition memory in monkeys. Behav Neural Biol 55: 61-67.

Alberini CM. 2005. Mechanisms of memory stabilization: are consolidation and reconsolidation similar or distinct processes? Trends Neurosci 28: 51-56.

Aloisi AM, Casamenti F, Scali C, Pepeu G, Carli G. 1997. Effects of novelty, pain and stress on hippocampal extracellular acetylcholine levels in male rats. Brain Res 748: $219-226$.

Balderas I, Rodriguez-Ortiz CJ, Bermudez-Rattoni F. 2013. Retrieval and reconsolidation of object recognition memory are independent processes in the perirhinal cortex. Neuroscience 253: 398-405.

Ben Mamou C, Gamache K, Nader K. 2006. NMDA receptors are critical for unleashing consolidated auditory fear memories. Nat Neurosci 9: 1237-1239.

Brown MW, Barker GR, Aggleton JP, Warburton EC. 2012. What pharmacological interventions indicate concerning the role of the perirhinal cortex in recognition memory. Neuropsychologia 50: 3122-3140.

Buckley MJ. 2005. The role of the perirhinal cortex and hippocampus in learning, memory, and perception. QJ Exp Psychol B 58: 246-268.

Burwell RD. 2001. Borders and cytoarchitecture of the perirhinal and postrhinal cortices in the rat. J Comp Neurol 437: 17-41.

Choi JH, Kim JE, Kaang BK. 2010. Protein synthesis and degradation are required for the incorporation of modified information into the pre-existing object-location memory. Mol Brain 3: 1 .

Eisenberg M, Dudai Y. 2004. Reconsolidation of fresh, remote, and extinguished fear memory in Medaka: old fears don't die. Eur J Neurosci 20: $3397-3403$.

Ennaceur A. 2010. One-trial object recognition in rats and mice: methodological and theoretical issues. Behav Brain Res 215: 244-254.

Ennaceur A, Delacour J. 1988. A new one-trial test for neurobiological studies of memory in rats. 1: Behavioral data. Behav Brain Res 31: 47-59.

Fernández de Sevilla D, Núñez A, Borde M, Malinow R, Buño W. 2008. Cholinergic-mediated IP3-receptor activation induces long-lasting synaptic enhancement in CA1 pyramidal neurons. J Neurosci 28: $1469-1478$.

Forcato C, Rodriguez ML, Pedreira ME, Maldonado H. 2010. Reconsolidation in humans opens up declarative memory to the entrance of new information. Neurobiol Learn Mem 93: 77-84.

Forwood SE, Winters BD, Bussey TJ. 2005. Hippocampal lesions that abolish spatial maze performance spare object recognition memory at delays of up to 48 hours. Hippocampus 15: 347-355.

Giovannini MG, Rakovska A, Benton RS, Pazzagli M, Bianchi L, Pepeu G. 2001. Effects of novelty and habituation on acetylcholine, GABA, and glutamate release from the frontal cortex and hippocampus of freely moving rats. Neuroscience 106: 43-53.

Hasselmo ME, McGaughy J. 2004. High acetylcholine levels set circuit dynamics for attention and encoding and low acetylcholine levels set dynamics for consolidation. Prog Brain Res 145: 207-231. 
Hong I, Kim J, Kim J, Lee S, Ko HG, Nader K, Kaang BK, Tsien RW, Choi S. 2013. AMPA receptor exchange underlies transient memory destabilization on retrieval. Proc Natl Acad Sci 110: 8218-8223.

Hupbach A, Gomez R, Hardt O, Nadel L. 2007. Reconsolidation of episodic memories: a subtle reminder triggers integration of new information. Learn Mem 14: 47-53.

Ihalainen J, Sarajarvi T, Kemppainen S, Keski-Rahkonen P, Lehtonen M, Tanila H. 2010. A novel delayed non-match to sample object recognition task that allows simultaneous in vivo microdialysis. $J$ Neurosci Methods 189: 210-215.

Inglis FM, Fibiger HC. 1995. Increases in hippocampal and frontal cortical acetylcholine release associated with presentation of sensory stimuli. Neuroscience 66: 81-86.

Kaang BK, Choi JH. 2011. Protein degradation during reconsolidation as a mechanism for memory reorganization. Front Behav Neurosci 5: 2 .

Lee JL. 2008. Memory reconsolidation mediates the strengthening of memories by additional learning. Nat Neurosci 11: 1264-1266.

Lee JL. 2009. Reconsolidation: maintaining memory relevance. Trends Neurosci 32: 413-420.

Lee SH, Choi JH, Lee N, Lee HR, Kim JI, Yu NK, Choi SL, Kim H, Kaang BK. 2008. Synaptic protein degradation underlies destabilization of retrieved fear memory. Science 319: 1253-1256.

Lewis DJ. 1979. Psychobiology of active and inactive memory. Psychol Bull 86: $1054-1083$.

Milekic MH, Alberini CM. 2002. Temporally graded requirement for protein synthesis following memory reactivation. Neuron 36: 521-525.

Milton AL, Merlo E, Ratano P, Gregory BL, Dumbreck JK, Everitt BJ. 2013. Double dissociation of the requirement for GluN2B- and GluN2A-containing NMDA receptors in the destabilization and restabilization of a reconsolidating memory. J Neurosci 33: 1109-1115.

Morris RG, Inglis J, Ainge JA, Olverman HJ, Tulloch J, Dudai Y, Kelly PA. 2006. Memory reconsolidation: sensitivity of spatial memory to inhibition of protein synthesis in dorsal hippocampus during encoding and retrieval. Neuron 50: 479-489.

Murray EA, Bussey TJ, Saksida LM. 2007. Visual perception and memory: a new view of medial temporal lobe function in primates and rodents. Annu Rev Neurosci 30: 99-122.

Nader K, Hardt O. 2009. A single standard for memory: the case for reconsolidation. Nat Rev Neurosci 10: 224-234.

Nader K, Schafe GE, Le Doux JE. 2000. Fear memories require protein synthesis in the amygdala for reconsolidation after retrieval. Nature 406: $722-726$.

Nilsson OG, Kalén P, Rosengren E, Björklund A. 1990. Acetylcholine release in the rat hippocampus as studied by microdialysis is dependent on axonal impulse flow and increases during behavioural activation. Neuroscience 36: 325-338.

Passetti F, Dalley JW, O'Connell MT, Everitt BJ, Robbins TW. 2000. Increased acetylcholine release in the rat medial prefrontal cortex during performance of a visual attentional task. Eur J Neurosci 12: 3051-3058.

Paxinos G, Watson C. 1998. The rat brain in stereotaxic coordinates. Academic Press, London.

Reichelt AC, Exton-McGuinness MT, Lee JL. 2013. Ventral tegmental dopamine dysregulation prevents appetitive memory destabilization. $J$ Neurosci 33: 14205-14210.

Rodriguez-Ortiz CJ, De la Cruz V, Gutiérrez R, Bermudez-Rattoni F. 2005. Protein synthesis underlies post-retrieval memory consolidation to a restricted degree only when updated information is obtained. Learn Mem 12: 533-537.
Romero-Granados R, Fontan-Lozano A, Delgado-Garcia JM, Carrión AM. 2010. From learning to forgetting: behavioral, circuitry, and molecular properties define the different functional states of the recognition memory trace. Hippocampus 20: 584-595.

Rossato JI, Bevilaqua LR, Myskiw JC, Medina JH, Izquierdo I, Cammarota M. 2007. On the role of hippocampal protein synthesis in the consolidation and reconsolidation of object recognition memory. Learn Mem 14: $36-46$.

Sara SJ. 2000. Retrieval and reconsolidation: toward a neurobiology of remembering. Learn Mem 7: 73-84.

Sarter M, Bruno JP. 1997. Cognitive functions of cortical acetylcholine: toward a unifying hypothesis. Brain Res Brain Res Rev 23: 28-46.

Sevenster D, Beckers T, Kindt M. 2013. Prediction error governs pharmacologically induced amnesia for learned fear. Science 339: 830-833.

Suzuki A, Josselyn SA, Frankland PW, Masushige S, Silva AJ, Kida S. 2004. Memory reconsolidation and extinction have distinct temporal and biochemical signatures. J Neurosci 24: 4787-4795.

Suzuki A, Mukawa T, Tsukagoshi A, Frankland PW, Kida S. 2008. Activation of LVGCCs and CB1 receptors required for destabilization of reactivated contextual fear memories. Learn Mem 15: 426-433.

Tang Y, Aigner TG. 1996. Release of cerebral acetylcholine increases during visually mediated behavior in monkeys. Neuroreport 7: 2231-2235.

Tang Y, Mishkin M, Aigner TG. 1997. Effects of muscarinic blockade in perirhinal cortex during visual recognition. Proc Natl Acad Sci 94: 12667-12669.

Tronson NC, Taylor JR. 2007. Molecular mechanisms of memory reconsolidation. Nat Rev Neurosci 8: 262-275.

Warburton EC, Koder T, Cho K, Massey PV, Duguid G, Barker GR, Aggleton JP, Bashir ZI, Brown MW. 2003. Cholinergic neurotransmission is essential for perirhinal cortical plasticity and recognition memory. Neuron 38: 987-996.

Winters BD, Forwood SE, Cowell RA, Saksida LM, Bussey TJ. 2004. Double dissociation between the effects of peri-postrhinal cortex and hippocampal lesions on tests of object recognition and spatial memory: heterogeneity of function within the temporal lobe. J Neurosci 24: $5901-5908$

Winters BD, Saksida LM, Bussey TJ. 2006. Paradoxical facilitation of object recognition memory after infusion of scopolamine into perirhinal cortex: implications for cholinergic system function. J Neurosci 26: 9520-9529.

Winters BD, Bartko SJ, Saksida LM, Bussey TJ. 2007. Scopolamine infused into perirhinal cortex improves object recognition memory by blocking the acquisition of interfering object information. Learn Mem 14: $590-596$.

Winters BD, Saksida LM, Bussey TJ. 2008. Object recognition memory: neurobiological mechanisms of encoding, consolidation and retrieval. Neurosci Biobehav Rev 32: 1055-1070.

Winters BD, Tucci MC, DaCosta-Furtado M. 2009. Older and stronger object memories are selectively destabilized by reactivation in the presence of new information. Learn Mem 16: 545-553.

Winters BD, Tucci MC, Jacklin DL, Reid JM, Newsome J. 2011. On the dynamic nature of the engram: evidence for circuit-level reorganization of object memory traces following reactivation. J Neurosci 31: $17719-17728$.

Received November 27, 2014; accepted in revised form December 22, 2014. 


\section{Corrigendum}

Learning and Memory 22: 203-214 (2015)

\section{Corrigendum: Cholinergic manipulations bidirectionally regulate object memory} destabilization

Mikaela L. Stiver, Derek L. Jacklin, Krista A. Mitchnick, Nevena Vicic, Justine Carlin, Matthew O’Hara, and Boyer D. Winters

In Figures 4, 6, 9, and 10, the procedural schematic above each graph depicts a 72-h delay between sample (S) and reactivation (RA) phases. However, as stated correctly in the Materials and Methods section, this delay was actually 48 h, as described in our previous study (Winters et al. 2009, LearnMem 16: 545-553).

This error is also present in the Figure 4 legend, panel $A$, where $72 \mathrm{~h}$ should read $48 \mathrm{~h}$.

doi: $10.1101 / \mathrm{lm} .039883 .115$ 


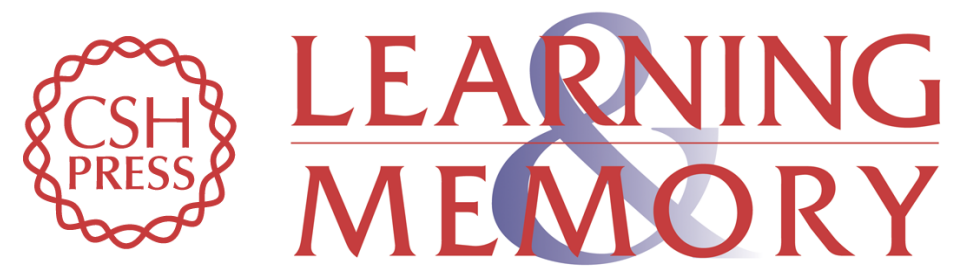

\section{Cholinergic manipulations bidirectionally regulate object memory destabilization}

Mikaela L. Stiver, Derek L. Jacklin, Krista A. Mitchnick, et al.

Learn. Mem. 2015, 22:

Access the most recent version at doi:10.1101/Im.037713.114

\section{Supplemental http://learnmem.cshlp.org/content/suppl/2015/03/09/22.4.203.DC1 \\ Material}

Related Content Corrigendum: Cholinergic manipulations bidirectionally regulate object memory destabilization

Mikaela L. Stiver, Derek L. Jacklin, Krista A. Mitchnick, et al.

Learn. Mem. October , 2015 22: 526

References This article cites 53 articles, 18 of which can be accessed free at:

http://learnmem.cshlp.org/content/22/4/203.full.html\#ref-list-1

Articles cited in:

http://learnmem.cshlp.org/content/22/4/203.full.html\#related-urls

Creative This article is distributed exclusively by Cold Spring Harbor Laboratory Press for the

Commons first 12 months after the full-issue publication date (see

License http://learnmem.cshlp.org/site/misc/terms.xhtml). After 12 months, it is available under a Creative Commons License (Attribution-NonCommercial 4.0 International), as described at http://creativecommons.org/licenses/by-nc/4.0/.

Email Alerting Receive free email alerts when new articles cite this article - sign up in the box at the Service top right corner of the article or click here. 